\title{
Is There Safety in the Use of Clopidogrel Loading Dose in Patients Over 75 Years of Age with Acute Coronary Syndrome?
}

Alexandre de Matos Soeiro, Guilherme Casale, ${ }^{\circledR}$ Maria Antonieta Albanez Albuquerque de Medeiros Lopes, Lucas Colombo Godoy, ${ }^{\circledR}$ Aline Siqueira Bossa, ${ }^{\circledR}$ Bruno Biselli, ${ }^{\oplus}$ Tatiana de Carvalho Andreucci Torres Leal, ${ }^{\circledR}$ Maria Carolina Feres de Almeida Soeiro, ${ }^{\circledR}$ Carlos V. Serrano Jr., ${ }^{\oplus}$ Múcio Tavares Oliveira Jr.

Unidade Clínica de Emergência - InCor - HCFMUSP - São Paulo, SP - Brazil

\section{Abstract}

Background: There is limited evidence in the literature regarding the administration of clopidogrel to acute coronary syndrome (ACS) in patients over 75 years of age. Most studies excluded this age group, making the subject controversial due to the increased risk of bleeding in this population.

Objective: This is a retrospective, unicentric, and observational study aimed at assessing whether the administration of clopidogrel loading dose increases bleeding rates in patients over 75 years of age.

Methods: Patients were divided into two groups: group I: 75 mg of clopidogrel; group II: 300-to 600-mg loading dose of clopidogrel. A total of 174 patients (129 in group I and 45 in group II) were included between May 2010 and May 2015. Statistical analysis: The primary outcome was bleeding (major and/or minor). The secondary outcome was combined events (cardiogenic shock, reinfarction, death, stroke and bleeding). The comparison between groups was performed through Q-square and T-test. The multivariate analysis was performed by logistic regression, being considered significant $\mathrm{p}<0.05$.

Results: Comparisons between groups I and II showed differences in the prevalence of diabetes (46.5\% vs. $24.4 \%$, p $=0.01)$, arterial hypertension ( $90.7 \%$ vs. $75, \mathrm{p}=0.01)$, dyslipidemia $(62 \%$ vs. $42.2 \%, \mathrm{p}=0.021)$, ST segment elevation $(11.6 \%$ vs. $26.6 \%, \mathrm{p}=0.016)$ and coronary intervention percutaneous ( $16.5 \%$ vs. $62.2 \%, \mathrm{p}<0.0001)$, respectively. In the multivariate analysis, significant differences were observed between groups I and II in relation to the occurrence of bleeding ( $8.5 \%$ vs. $20 \%$, OR $=0.173,95 \%$ CI: $0.049-0.614, \mathrm{p}=0.007$ ).

Conclusion: The use of a loading dose of clopidogrel $(\geq 300 \mathrm{mg})$ in the population over 75 years of age is associated with higher bleeding rates. (Int J Cardiovasc Sci. 2019;32(5):449-456)

Keywords: Platelet Aggregation Inhibitors/therapeutic use; Acute Coronary Syndrome/complications; Aged; Hemorrhage; Treatment Outcome.

\section{Introduction}

Among the elderly population, only $40 \%$ of patients over 75 years of age receive reperfusion therapy in the United States. ${ }^{1}$ Consistent with these numbers, a recent study in England found that older patients were incrementally less likely to receive invasive and medical therapy. ${ }^{2}$ Current guidelines do not suggest any age-related limitations of medical or invasive therapy, stating that percutaneous coronary intervention (PCI) in acute coronary syndrome (ACS) is beneficial for elderly patients. ${ }^{3-8}$

However, there is little evidence in the literature concerning the use of loading dose of clopidogrel in patients aged over 75 years with ACS. Most randomized studies have excluded this age group, and hence there is limited data available, which makes the subject controversial, due to increased bleeding risk in this population. ${ }^{1}$ The description of these comparative data in Brazilian registries has not yet been documented. 
Thus, this study was developed with the purpose of assessing whether the administration of a $300 \mathrm{mg}$ or $600 \mathrm{mg}$ loading dose of clopidogrel increases in-hospital bleeding rates in patients over 75 years of age.

\section{Methods}

\section{Study population}

This is a retrospective, unicentric and observational study. We included 174 (12.9\% of total) individuals with ACS aged $>75$ years, admitted to the emergency sector between May 2010 and May 2015. The patients were divided into two groups: group I: $75 \mathrm{mg}$ loading dose of clopidogrel $(\mathrm{N}=129)$; group II: 300 to $600 \mathrm{mg}$ loading dose of clopidogrel $(\mathrm{N}=45)$. There were no additional exclusion criteria.

All patients who met the criteria established by the latest guidelines of the Brazilian Society of Cardiology and the American Heart Association were considered to have had ACS. ${ }^{3,4}$ ACS with no ST segment elevation was defined as the presence of chest pain associated with electrocardiographic alterations or rise/drop of troponin upon admission, or, in the absence of these factors, a clinical picture and risk factors consistent with unstable angina (chest pain when resting or with minimal effort, severe pain, or with an improving pattern). Major bleeding was defined by the score of BARC ${ }^{9}$ types 3 and 5 , and minor bleeding by types 1 and 2 . Reinfarction was considered in cases of recurrence of chest pain linked to the new troponin elevation. Ischemic cerebrovascular accident (iCVA) was considered when the patient displayed new focal motor neurological deficit confirmed through cranial computerized tomography.

All patients underwent coronary angiography within the first $24 \mathrm{~h}$ after admission. All percutaneous coronary interventions (PCI) were performed with conventional stents.

The following data were obtained: age, sex, presence of diabetes mellitus, systemic arterial hypertension, smoking, dyslipidemia, family history of early coronary disease, heart failure, previous coronary artery disease (acute myocardial infarction, angioplasty or previous surgical myocardial revascularization), hemoglobin, creatinine, troponin peak, left ventricular ejection fraction, systolic blood pressure, medications used within the first 24 hours of admission and the coronary treatment adopted.

This study was submitted and approved by the Research Ethics Committee. The written informed consent form was signed by all patients included in the study.

\section{Statistical analysis}

The primary in-hospital outcome was bleeding. The secondary outcome was combined events (cardiogenic shock, reinfarction, death, stroke and bleeding). The descriptive analysis was done using means and standard deviation when parametric tests were used and median and interquartile intervals in non-parametric tests. The comparison between groups was made through Q-square for the categorical variables. For continuous variables, when the Komolgorov-Smirnov normality test showed normal distribution, the variables were calculated using the T-test, considering as significant $\mathrm{p}<0.05$. When the distribution did not follow the normality standard, we used the Mann-Whitney U test. An additional univariate analysis was conducted through Q-square test, comparing mortality between patients who bled versus those who did not present the outcome and also comparing major bleeding rates between groups I and II. The multivaried analysis was performed through logistic regression only when a significant difference was found between the groups in any of the outcomes assessed, and considering as significant $\mathrm{p}<0.05$. All baseline characteristics presented by Table 1 were considered as variables in the analysis.

All calculations were performed using the SPSS Statistics Base v10.0 software.

\section{Results}

The mean age was 80.2 years in group I versus 80.5 years in group II $(p=0.728)$. The baseline characteristics of the population studied are presented by Table 1 .

In relation to the treatment, the performance of PCI was observed in $16.5 \%$ in group I and $62.2 \%$ in group II ( $\mathrm{p}<0.0001)$. Surgical myocardial revascularization was performed in $9.3 \%$ of group I versus $4.4 \%$ of group II $(\mathrm{p}=0.302)$.

In the univariate and multivariate analysis, significant differences were observed between groups I and II in relation to bleeding rates $(8.5 \%$ vs. $20 \%, \mathrm{OR}=0.173 ; 95 \%$ CI: $0.049-0.614, p=0.007)$, respectively. The results of the univariate and multivariate analysis, comparing different in-hospital outcomes between the groups, are presented by Table 2 . 
Table 1 - Baseline clinical characteristics of elderly ACS patients who received $75 \mathrm{mg}$ clopidogrel (group I) versus 300 - $600 \mathrm{mg}$ clopidogrel (group II) in the sample studied

\begin{tabular}{|c|c|c|c|}
\hline & Group I & Group II & $\mathbf{p}$ \\
\hline Age (mean) & $80.2+4.3$ & $80.5+4.7$ & $0.728 \pi$ \\
\hline Diabetes Mellitus (\%) & 46.5 & 24.4 & $0.01 \#$ \\
\hline $\mathrm{SAH}(\%)$ & 90.7 & 75.6 & $0.01 \#$ \\
\hline Smoking (\%) & 30.2 & 17.8 & $0.105 \#$ \\
\hline $\begin{array}{l}\text { Positive FH for CAD } \\
(\%)\end{array}$ & 8.5 & 6.7 & $0.693 \#$ \\
\hline Dislypidemia (\%) & 62 & 42.2 & $0.021 \#$ \\
\hline $\mathrm{CI}(\%)$ & 7.9 & 4.4 & $0.451 \#$ \\
\hline Previous CVA (\%) & 10.1 & 6.7 & $0.495 \#$ \\
\hline Previous AMI $(\%)$ & 37.2 & 42.2 & $0.552 \#$ \\
\hline Previous SMR (\%) & 15.5 & 22.2 & $0.304 \#$ \\
\hline Previous TCA (\%) & 26.4 & 35.6 & $0.24 \#$ \\
\hline $\mathrm{Hb}(\mathrm{mg} / \mathrm{dL})$ (mean) & $14.6+1.9$ & $13.2+1.7$ & $<0.001 \pi$ \\
\hline $\begin{array}{l}\text { Troponin peak (mean) } \\
\text { (ng/dL) }\end{array}$ & $11.8+5.9$ & $8.0+7.2$ & $<0.001 \pi$ \\
\hline $\mathrm{Cr}(\mathrm{mg} / \mathrm{dL})$ (mean) & $1.3+0.5$ & $1.5+0.4$ & $<0.0001 \pi$ \\
\hline SBP (mmHg) (mean) & $134.2+29.4$ & $133.0+27.2$ & $0.104 \pi$ \\
\hline LVEF (\%) (mean) & $52.3+19.9$ & $51.8+18.7$ & $0.09^{*}$ \\
\hline STEMI (\%) & 11.6 & 26.7 & $0.016 \#$ \\
\hline ASA $(\%)$ & 98.4 & 100 & $0.401 \#$ \\
\hline Beta-blockers (\%) & 51.2 & 40 & $0.197 \#$ \\
\hline GPI IIb / IIIa (\%) & 5.4 & 0 & $0.111 \#$ \\
\hline Enoxaparin $(\%)$ & 74.4 & 71.1 & $0.665 \#$ \\
\hline Fibrinolytic (\%) & 2.3 & 0 & $0.302 \#$ \\
\hline Statins $(\%)$ & 82.2 & 95.6 & $0.088 \#$ \\
\hline $\operatorname{ACEi}(\%)$ & 49.6 & 53.3 & $0.667 \#$ \\
\hline
\end{tabular}

SBP: systolic blood pressure; SAH: systemic arterial hypertension; FH: family history; CAD: coronary artery disease; HF: heart failure; CVA: cerebral vascular accident; AMI: acute myocardial infarction; SMR: surgical myocardial revascularization; TCA: coronary angioplasty; Hb: hemoglobin; Cr: creatinine; LVEF: left ventricular ejection fraction; GPI: glycoprotein inhibitor; ACEi: AngiotensinConverting Enzyme Inhibitor. \#: Q-square test; *: Student's t-test; $\pi$ : Mann-Whitney U test.

As for the incidence of hemorrhagic complications, the most frequent was hemorrhagic stroke (50\% of cases), followed by femoral artery puncture (35\%), epistaxis
(10\%) and hemarthrosis (5\%). Major bleeding occurred in $45.5 \%$ of patients in group I and $44.4 \%$ in group II $(p=0.672)$. Mortality rate among patients who had any type of bleeding versus those who had no bleeding was $25 \%$ vs. $4.5 \%(\mathrm{p}<0.0001)$. Types of bleeding per group can be observed in Figure 1. The types of vascular accesses were also similar between the groups, with radial access being used in $48 \%$ of patients in group I and $51 \%$ in group II $(\mathrm{p}=0.347)$.

\section{Discussion}

This study showed important data reproduced in the Brazilian population on a controversial issue in the literature. We reported higher reperfusion rates (especially percutaneous) and ACS with ST elevation in patients in group II, in a significant manner. In relation to bleeding, significant differences were observed, with a higher incidence in patients who received clopidogrel (300-mg to 600-mg loading dose). Furthermore, hemorrhagic stroke was the most prevalent bleeding disorder and the occurrence of any bleeding (major or minor) had an impact on higher in-hospital mortality rates. Nevertheless, in the comparison between groups I and II there were no differences regarding mortality and combined events.

The current guidelines recommend the use of full treatment and loading dose of clopidogrel in patients aged over 75 years, without almost any distinction when compared to younger patients. The current guidelines of the American Heart Association, the European Society of Cardiology or the Brazilian Society of Cardiology, ${ }^{3-8}$ suggest that the $600-\mathrm{mg}$ loading dose is preferable in all patients undergoing PCI. The only exception, which contemplates the elderly, refers to patients aged over 75 years undergoing fibrinolytic therapy, for whom only the dose of $75 \mathrm{mg}$ clopidogrel is recommended, with no additional loading dose..$^{3-8}$ However, until 2015, in Brazil, the guidelines recommended that only the 75-mg clopidogrel dose should be administered to all patients aged over 75 years, with no loading dose..$^{10}$ This recent change in the guidelines allowed for a retrospective analysis of data and the assessment of the safety of the use of clopidogrel in older patients undergoing invasive procedures, following the previous recommendation in contrast with the new recommendation, since fibrinolytics were used in less than $2 \%$ of cases.

The most cautious recommendation concerning the elderly, which prevailed until 2015, came primarily from 
Table 2 - A. Results of the univariate analysis comparing different in-hospital outcomes in elderly ACS patients who received $75 \mathrm{mg}$ clopidogrel (group I) versus 300 - $600 \mathrm{mg}$ clopidogrel (group II); B. Results of the multivariate analysis comparing different bleeding among elderly ACS patients who received $75 \mathrm{mg}$ clopidogrel (group I) versus 300 - 600 mg clopidogrel (group II)

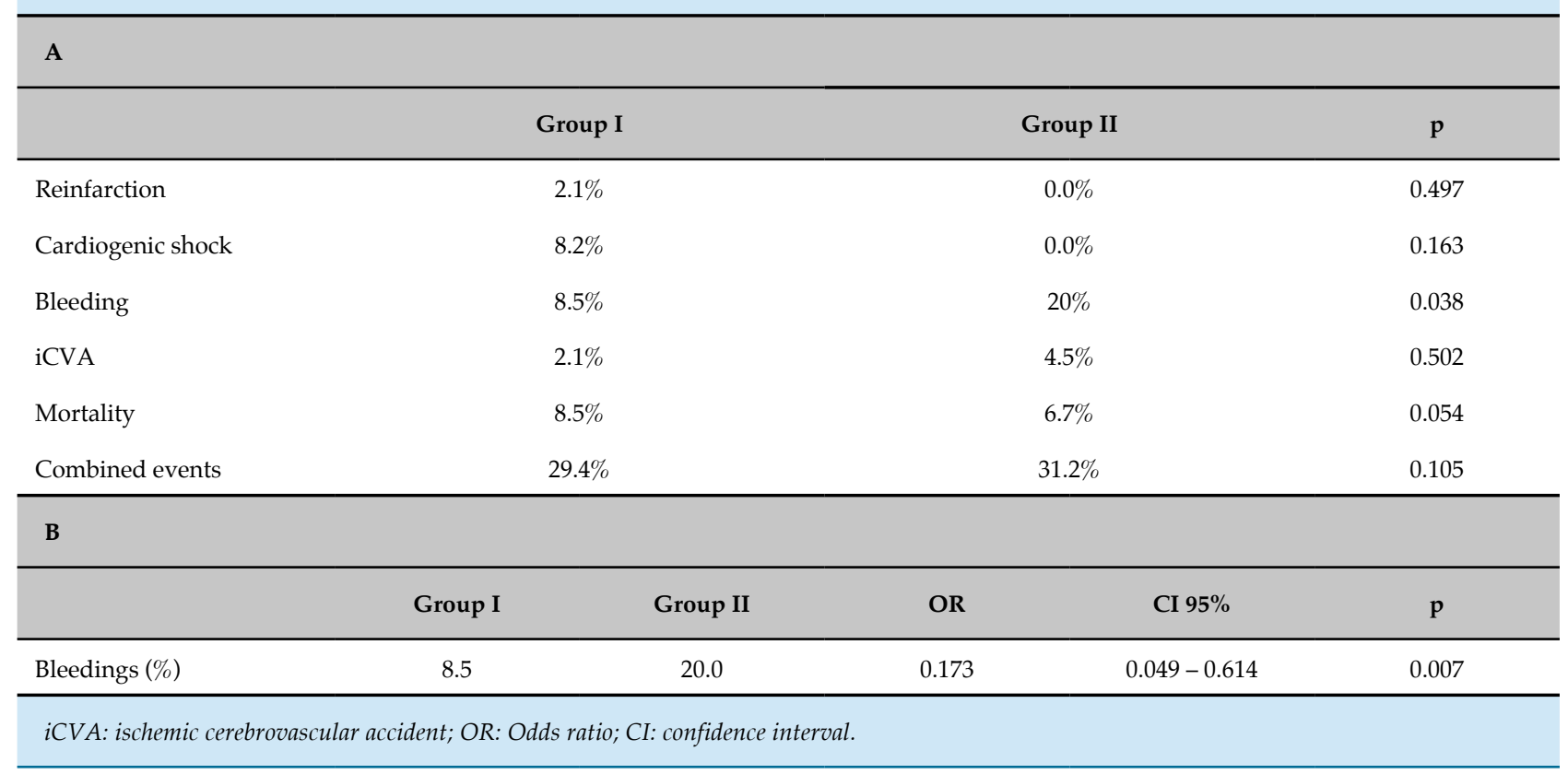

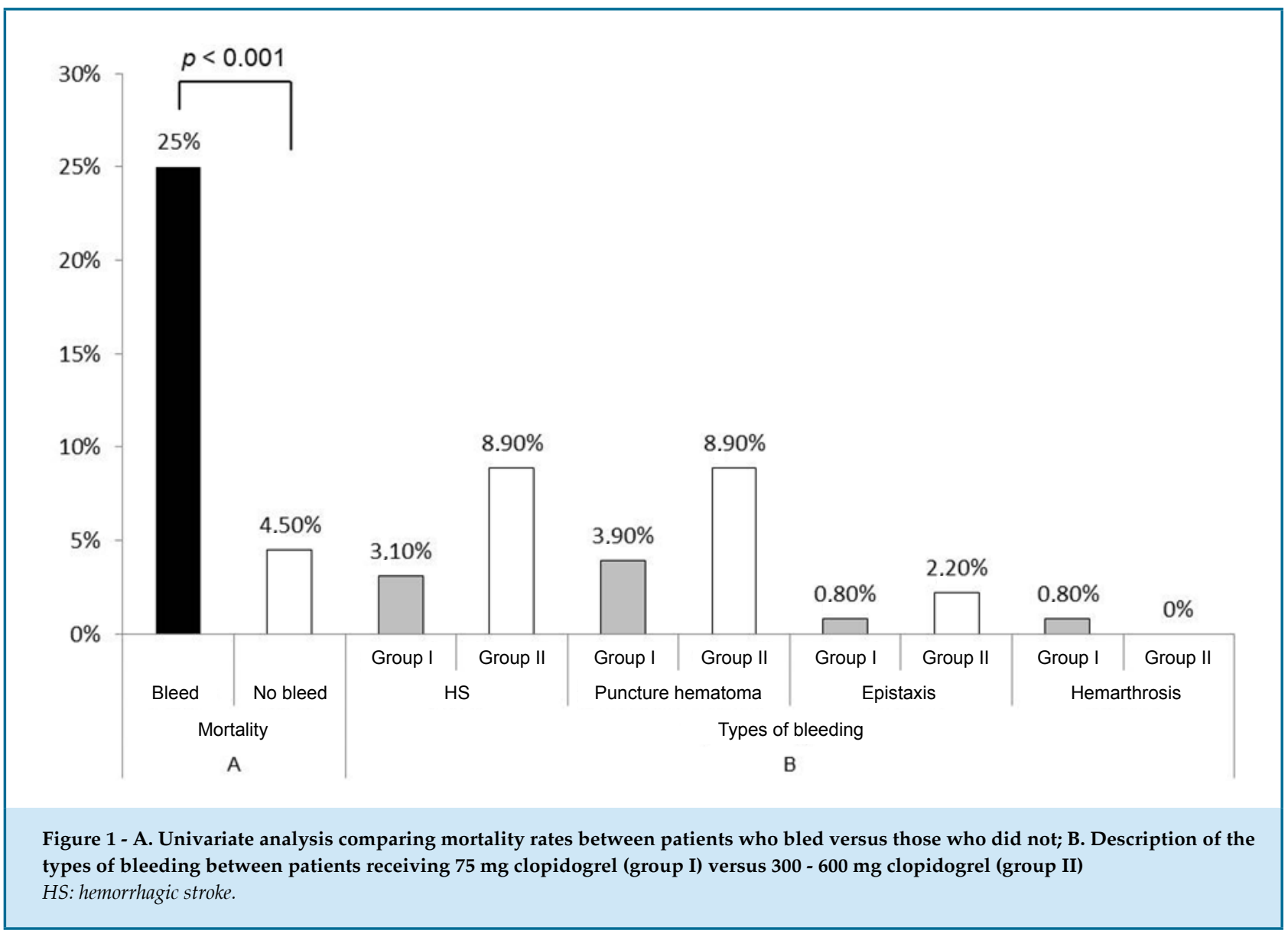


the COMMIT/CCS-2 studies, carried out exclusively in China, which included more than 40,000 patients with acute myocardial infarction (AMI). The patients were randomly allocated clopidogrel $75 \mathrm{mg}$ daily (no loading dose) or matching placebo. Treatment with clopidogrel produced a 9\% reduction in the co-primary outcomes: death, AMI or stroke. Safety outcomes (cerebral, transfusion and fatal bleeds) did not differ significantly among the groups (clopidogrel 0.58\% versus placebo $0.55 \% ; \mathrm{p}=0.59$ ). Although fibrinolytics were predominantly used in this study, there was an extrapolation and the recommendation was directed to all ACS-related cases. ${ }^{11}$

However, concerns with stent thrombosis and the use of clopidogrel started to bring new evidence into the discussion. It has been shown that there is mainly genetic resistance to clopidogrel, mechanisms that limit its absorption and lead to delayed metabolization. Hence, higher loading doses have been tested, especially in patients undergoing early PCI and who need the drug bioavailability in a short period of time. ${ }^{12-26}$ The greatest study was the CURRENTOASIS 7 trial, which included 25,086 patients with ACS and intended PCI (29\% with STE-ACS). Patients were assigned to double-dose (600 $\mathrm{mg}$ on day 1, $150 \mathrm{mg}$ on days 2-7, then $75 \mathrm{mg}$ daily) versus standard-dose (300 $\mathrm{mg}$ on day 1 then $75 \mathrm{mg}$ daily) clopidogrel. There was a significant decrease in primary outcome rates within a 30-day follow-up, especially due to reduced non-fatal infarction and stent thrombosis rates. However, the mean age of the patients included was only 61 years and major bleeding was more common in the group receiving the double-dose clopidogrel $(1.5 \%$ vs. $1.1 \%, \mathrm{p}=0.014) .{ }^{12}$ Since the net benefit was greater, high-dose clopidogrel started to be indicated and modifications were made in the guidelines, but specific subgroups, with a high risk of bleeding, were not taken into account, because they were not included in these studies.

Most studies of PCI in ACS patients normally exclude the elderly. When all clinical trials are considered, only about $9 \%$ of patients are over 75 years of age and the mean age ranges between 55 and 65 years. Nevertheless, in real clinical practice, about $35 \%$ of patients belong to this age group, whose baseline clinical characteristics are completely distinct from the rest of the population. ${ }^{1,24,27}$ A study conducted in 2011, specifically in patients aged 75 years or older, compared the platelet reactivity and clopidogrel response between patients aged $>75$ years and $<75$ years undergoing PCI for non-ST-segment elevation ACS. A total of 689 patients were enrolled and all of them received a loading dose of $600 \mathrm{mg}$ clopidogrel followed by $150 \mathrm{mg} /$ day. Post-treatment platelet reactivity was higher in patients older than 75 years of age than in younger patients. However, the pharmacologic response to clopidogrel was not impaired in patients $>75$ years, not showing a relationship between platelet reactivity and response to the drug. ${ }^{28}$ Besides, the group of patients aged over 75 years had higher bleeding rates $(12 \%$ vs. $8 \%, \mathrm{p}=0.03)$ compared to younger patients. ${ }^{28}$

Lin et al., ${ }^{29}$ also carried out a study on the effect of antiplatelet therapy on elderly patients. They tested standard versus low-dose tirofiban in elderly patients ( $>80$ years) who underwent PCI. The rate of combined ischemic events was not significantly different at 7 days, 30 days and 6 months. Bleeding events were significantly higher in the standard-dose group (10.4\% vs. $0.0 \%, \mathrm{p}=0.03$ ). The authors concluded that, in very elderly high-risk patients undergoing PCI, low-dose tirofiban offered the same level of protection, with less associated bleeding. ${ }^{29}$

Data from a German STEMI registry compared patients aged under 75 years (group I), between 75 and 85 years (group II) and over 85 years (group III). Bleeding was observed more often with increasing age (group I: $5.4 \%$ vs. group 2: $11.0 \%$ vs. group 3: $19.6 \%$, $\mathrm{p}<0.0001)$. Similarly and directly related, mortality rates during in-hospital and long-term course increased with increasing age. ${ }^{30}$ Classically, bleeding is associated with a fourfold increased risk of death, a five-fold increased risk of reinfarction and a threefold increased risk of stroke. The need for suspension of antiplatelet/anticoagulant drugs increases the risk of ischemic events, especially stent thrombosis. ${ }^{31}$

Similarly, the CRUSADE registry assessed bleeding rates in 32,895 NSTE-ACS patients aged over 65 years and their impact on mortality rates among this group. About $11.9 \%$ of the patients had major bleeding during hospital stay. Mortality rates were higher among those patients who had major bleeding compared to those with no bleeding, both within 30 days ( $\mathrm{HR}=1.33$; 95\% CI: 1.18 - 1.51], 1 year $(\mathrm{HR}=1.19 ; 95 \%$ CI: $1.10-1.29)$ and also within 3 years $(1.14 ; 95 \%$ CI: $0.99-1.31) .{ }^{32}$

Thus, the greatest concern in relation to patients aged over 75 years is to find a balance between the 
appropriate pharmacological invasive treatment and the risk of bleeding and complications inherent to this age group. This study presents a change in bleeding rates that has a total correlation with the stance adopted by the guidelines. In spite of a greater number of ACS patients with ST-segment elevation and those undergoing PCI in the group who received clopidogrel loading dose, this study did not find any differences between the groups in relation to medications, performance of invasive procedures, number of radial vascular accesses and possible confounding variables adjusted for in the multivariate analysis. Still, bleeding remained as the independent and differential factor between the groups. Due to lack of strong evidence in this population, perhaps non-ST-segment ACS patients undergoing PCI in a range greater than 4 to 6 hours should receive doses less than $600 \mathrm{mg}$ clopidogrel. Furthermore, it would be interesting and necessary to develop a randomized clinical trial to establish the best clinical therapy for the subgroup of patients aged over 75 years. Finally, the model of events prediction is hardly applicable to this population. The ideal would be to have a score which took into account frailty, dementia, level of dependence and other intrinsic characteristics of the elderly. ${ }^{1,33,34}$

\section{Limitations}

This is a retrospective study, with limited number of cases and a much greater number of patients in group I, compared to group II, since medication doses were administered according to the instructions of the doctor responsible for the case. Therefore, some more specific comparisons were not performed. Analysis of mortality and reinfarction cannot be inferred in this study. Nevertheless, we believe this study to be relevant, since guidelines are discordant and there is few data available in the literature on this issue.

\section{References}

1. Mazhari R, Kapur N. Increased risk and increased reward in coronary intervention in older patients with acute coronary syndrome. Heart. 2014;100(19):1483-4

2. Zaman MJ, Stirling S, Shepstone L, Ryding A, Flather M, Bachmann $\mathrm{M}$, et al. The association between older age and receipt of care and outcomes in patients with acute coronary syndromes: a cohort study of the Myocardial Ischaemia National Audit Project (MINAP). Eur Heart J. 2014;35(23):1551-8.

\section{Conclusion}

The use of a loading dose of clopidogrel ( $\geq 300 \mathrm{mg}$ ) in the population over 75 years of age is associated with higher bleeding rates.

\section{Author contributions}

Conception and design of the research: Alexandre Soeiro, Guilherme Casale; Acquisition of data: Alexandre Soeiro, Guilherme Casale, Maria Antonieta A. A. M. Lopes, Lucas Colombo Godoy; Analysis and interpretation of the data: Aline Siqueira Bossa; Statistical analysis: Aline Siqueira Bossa; Writing of the manuscript: Alexandre Soeiro; Critical revision of the manuscript for intellectual content: Bruno Biselli, Tatiana C. A T. Leal, Maria Carolina F. A. Soeiro; Supervision / as the major investigador: Carlos V Serrano Jr., Múcio T. Oliveira Jr.

\section{Potential Conflict of Interest}

No potential conflict of interest relevant to this article was reported.

\section{Sources of Funding}

There were no external funding sources for this study.

\section{Study Association}

This study is not associated with any thesis or dissertation work.

\section{Ethics approval and consent to participate}

This study was approved by the Ethics Committee of the CAPPesq under the protocol number 881.656. All the procedures in this study were in accordance with the 1975 Helsinki Declaration, updated in 2013. Informed consent was obtained from all participants included in the study.

3. Nicolau JC, Timerman A, Marin-Neto JA, Piegas LS, Barbosa CJDG, Franci A, et al. Diretrizes da Sociedade Brasileira de Cardiologia sobre Angina Instável e Infarto Agudo do Miocárdio sem Supradesnível do Segmento ST. Arq Bras Cardiol. 2014;102(3 Suppl.1):1-61.

4. 2012 Writing Committee Members, Jneid H, Anderson JL, Wright RS, Adams CD, Bridges CR, et al. 2012 ACCF / AHA focused update of the guideline for the management of patients with unstable angina/NonST-elevation myocardial infarction (updating the 2007 guideline and 
replacing the 2011 focused update): a report of the American College of Cardiology Foundation/ American Heart Association Task Force on practice guidelines. Circulation. 2012;126(7):875-910.

5. Valgimigli M, Bueno H, Byrne RA, Collet JP, Costa F, Jeppsson A, et al. 2017 ESC focused update on dual antiplatelet therapy in coronary artery disease developed in collaboration with EACTS: The Task Force for dual antiplatelet therapy in coronary artery disease of the European Society of Cardiology (ESC) and of the European Association for Cardio-Thoracic Surgery (EACTS). Eur Heart J. 2018;39(3):213-60.

6. Piegas LS, Timerman A, Feitosa GS, Nicolau JC, Mattos LAP, Andrade MD, et al. V Diretriz da Sociedade Brasileira de Cardiologia sobre Tratamento do Infarto Agudo do Miocárdio com Supradesnível do Segmento ST. Arq Bras Cardiol. 2015;105(2 Suppl 1):1-105

7. Levine GN, Bates ER, Bittl JA, Brindis RG, Fihn SD, Fleisher LA, et al. 2016 ACC / AHA Guideline Focused Update on Duration of Dual Antiplatelet Therapy in Patients With Coronary Artery Disease: A Report of the American College of Cardiology/American Heart Association Task Force on Clinical Practice Guidelines: An Update of the 2011 ACCF/ AHA/SCAI Guideline for Percutaneous Coronary Intervention, 2011 ACCF / AHA Guideline for Coronary Artery Bypass Graft Surgery, 2012 ACC/AHA/ACP/AATS/PCNA/SCAI/STS Guideline for the Diagnosis and Management of Patients With Stable Ischemic Heart Disease, 2013 ACCF / AHA Guideline for the Management of ST-Elevation Myocardial Infarction, 2014 AHA / ACC Guideline for the Management of Patients With Non-ST-Elevation Acute Coronary Syndromes, and 2014 ACC/ AHA Guideline on Perioperative Cardiovascular Evaluation and Management of Patients Undergoing Noncardiac Surgery. Circulation. 2016;134(10):e123-55.

8. Ibanez B, James S, Agewall S, Antunes MJ, Bucciarelli-Ducci C, Bueno $\mathrm{H}$, et al. 2017 ESC Guidelines for the management of acute myocardial infarction in patients presenting with ST-segment elevation: The Task Force for the management of acute myocardial infarction in patients presenting with ST-segment elevation of the European Society of Cardiology (ESC). Eur Heart J. 2018;39(2):119-77.

9. Mehran R, Rao SV, Bahht DL, Gibson CM, Caixeta A, Eikelboom J, et al. Standardized bleeding definitions for cardiovascular clinical trials: a consensus report from the Bleeding Academic Research Consortium. Circulation. 2011;123(23):2736-47.

10. Andrade JP. IV Diretriz da Sociedade Brasileira de Cardiologia sobre Tratamento do Infarto Agudo do Miocárdio com Supradesnível do Segmento ST. Arq Bras Cardiol. 2009;93(6 Suppl. 2):e179-264.

11. Chen ZM, Jiang LX, Chen YP, Xie JX, Pan HC, Peto R, et al. Addition of clopidogrel to aspirin in 45,852 patients with acute myocardial infarction: randomised placebo-controlled trial. Lancet. 2005;366(9497):1607-21.

12. Mehta SR, Tanguay JF, Eikelboom JW, Jolly SS, Joyner CD, Granger CB, et al. Double-dose versus standard-dose clopidogrel and high-dose versus low-dose aspirin in individuals undergoing percutaneous coronary intervention for acute coronary syndromes (CURRENT-OASIS 7): a randomised factorial trial. Lancet. 2010;376(9748):1233-43.

13. Yong G, Rankin J, Ferguson L, Thom J, French J, Brieger D, et al. Randomized trial comparing 600- with 300-mg loading dose of clopidogrel in patients with non-ST elevation acute coronary syndrome undergoing percutaneous coronary intervention: results of the Platelet responsiveness to Aspirin and Clopidogrel and Troponin Increment after Coronary intervention in acute coronary lesions (PRACTICAL) trial. Am Heart J. 2009;157(1):60.e1-9.

14. Abuzahra M, Pillai M, Caldera A, Hartley WB, Gonzalez R, Bobek J, et al. Comparison of higher clopidogrel loading and maintenance dose to standard dose on platelet function and outcomes after percutaneous coronary intervention using drug-eluting stents. Am J Cardiol. 2008;102(4):401-3.

15. Dangas G, Mehran R, Guagliumi G, Caixeta A, Witzenbichler B, Aoki J, et al. Role of clopidogrel loading dose in patients with ST-segment elevation myocardial infarction undergoing primary angioplasty: results from the HORIZONS-AMI (harmonizing outcomes with revascularization and stents in acute myocardial infarction) trial. J Am Coll Cardiol. 2009;54(15):1438-46.
16. Lemesle G, Delhaye C, Sudre A, Broucqsault D, Rosey G, Bauters C, et al. Impact of high loading and maintenance dose of clopidogrel within the first 15 days after percutaneous coronary intervention on patient outcome. Am Heart J. 2009;157(2):375-82.

17. Montalescot G, Sideris G, Meuleman C, Bal-dit-Sollier C, Lellouche N, Steg PG, et al. A randomized comparison of high clopidogrel loading doses in patients with non-ST-segment elevation acute coronary syndromes: the ALBION (Assessment of the Best Loading Dose of Clopidogrel to Blunt Platelet Activation, Inflammation and Ongoing Necrosis) trial. J Am Coll Cardiol. 2006;48(5):931-8.

18. Cuisset T, Frere C, Quilici J, Morange PE, Nait-Saidi L, Carvajal J, et al Benefit of a $600-\mathrm{mg}$ loading dose of clopidogrel on platelet reactivity and clinical outcomes in patients with non-ST-segment elevation acute coronary syndrome undergoing coronary stenting. J Am Coll Cardiol. 2006;48(7):1339-45.

19. Fernandez A, Aboodi MS, Milewski K, Delgado JA, Rodríguez A, Granada JF. Comparison of adverse cardiovascular events and bleeding complications of loading dose of clopidogrel $300 \mathrm{mg}$ versus $600 \mathrm{mg}$ in stable patients undergoing elective percutaneous intervention (from the CADICE study). Am J Cardiol. 2011;107(1):6-9.

20. Sabatine MS, Cannon CP, Gibson CM, López-Sendón JL, Montalescot G, Theroux $\mathrm{P}$, et al. Effect of clopidogrel pretreatment before percutaneous coronary intervention in patients with ST-elevation myocardial infarction treated with fibrinolytics: the PCI-CLARITY study. JAMA. 2005;294(10):1224-32

21. Feldman DN, Fakorede F, Minutello RM, Bergman G, Moussa I, Wong SC. Efficacy of high-dose clopidogrel treatment $(600 \mathrm{mg})$ less than two hours before percutaneous coronary intervention in patients with non-ST-segment elevation acute coronary syndromes. Am J Cardiol. 2010;105(3):323-32

22. Choi CU, Rha SW, Oh DJ, Poddar KL, Na JO, Kim JW, et al. Standard versus high loading doses of clopidogrel in Asian ST-segment elevation myocardial infarction patients undergoing percutaneous coronary intervention: insights from the Korea Acute Myocardial Infarction Registry. Am Heart J. 2011;161(2):373-82.e1-3.

23. Gibson CM, Murphy SA, Pride YB, Kirtane AJ, Aroesty JM, Stein EB, et al Effects of pretreatment with clopidogrel on nonemergent percutaneous coronary intervention after fibrinolytic administration for ST-segment elevation myocardial infarction: a Clopidogrel as Adjunctive Reperfusion Therapy-Thrombolysis in Myocardial Infarction (CLARITY-TIMI) 28 study. Am Heart J. 2008;155(1):133-9.

24. Song YB, Hahn JY, Gwon HC, Chang SA, Lee SC, Choe YH, et al. A high loading dose of clopidogrel reduces myocardial infarct size in patients undergoing primary percutaneous coronary intervention: a magnetic resonance imaging study. Am Heart J. 2012;163(3):500-7.

25. Patti G, Colonna G, Pasceri V, Pepe LL, Montinaro A, Di Sciascio G. Randomized trial of high loading dose of clopidogrel for reduction of periprocedural myocardial infarction in patients undergoing coronary intervention: results from the ARMYDA-2 (Antiplatelet therapy for Reduction of MYocardial Damage during Angioplasty) study. Circulation. 2005;111(16):2099-106.

26. Mangiacapra F, Muller O, Ntalianis A, Trana C, Heyndrickx GR, Bartunek $\mathrm{J}$, et al. Comparison of 600 versus $300-\mathrm{mg}$ Clopidogrel loading dose in patients with ST-segment elevation myocardial infarction undergoing primary coronary angioplasty. Am J Cardiol. 2010;106(9):1208-11.

27. Fukushima K, Kobayashi Y, Kitahara H, Iwata Y, Nakayama T, Kuroda N, et al. Effect of 150-mg vs 300-mg loading doses of clopidogrel on platelet function in Japanese patients undergoing coronary stent placement. Circ J. 2008;72(8):1282-4.

28. Cuisset T, Quilici J, Grosdidier C, Fourcade L, Gaborit B, Pankert M, et al. Comparison of platelet reactivity and clopidogrel response in patients $\leq 75$ Years Versus $>75$ years undergoing percutaneous coronary intervention for non-ST-segment elevation acute coronary syndrome. Am J Cardiol. 2011;108(10):1411-6.

29. Lin YL, Chen LL, Luo YK, Zheng XC, Li WW. Benefit of standard versus low-dose tirofiban for percutaneous coronary intervention in very elderly 
patients with high-risk acute coronary syndrome. Acta Pharmacol Sin. 2009;30(5):553-8

30. Fach A, Bünger S, Zabrocki R, Schmucker J, Conradi P, Garstka D, et al. Comparison of Outcomes of Patients With ST-Segment Elevation Myocardial Infarction Treated by Primary Percutaneous Coronary Intervention Analyzed by Age Groups $(<75,75$ to 85 , and $>85$ Years); (Results from the Bremen STEMI Registry). Am J Cardiol. 2015;116(12):1802-9.

31. Eikelboom JW, Mehta SR, Anand SS, Xie C, Fox KA, Yusuf S. Adverse impact of bleeding on prognosis in patients with acute coronary syndromes. Circulation. 2006;114(8):774-82.
32. Lopes RD, Subherwal S, Holmes DN, Thomas L, Wang TY, Rao SV, et al. The association of in-hospital major bleeding with short-, intermediate-, and long-term mortality among older patients with non-ST-segment elevation myocardial infarction. Eur Heart J. 2012;33(16):2044-53.

33. Soeiro AM, Borba AP, Bossa AS, Zullino CN, Almeida Soeiro MCF, Leal TCAT, et al. A risk-adjusted retrospective data analysis between younger and elderly aatients with acute coronary syndromes-long-term prognosis. Open J Emerg Med. 2016;4(3):53-61.

34. Soeiro AM, Silva PG, Roque EA, Bossa AS, César MC, Simões SA, et al. Fondaparinux versus Enoxaparin - Which is the Best Anticoagulant for Acute Coronary Syndrome? - Brazilian Registry Data. Arq Bras Cardiol. 2016; | 107(3):239-44 